\title{
Experimental and CFD Investigation the Effect of Solid Particle Height in Water-Solid Flow in Fluidized Bed Column
}

\author{
Riyadh S. Al-Turaihi, Sarah H. Oleiwi \\ Mechanical Department, College of Engineering, Babylon University, Babylon, Iraq \\ Email address: \\ drriyadhalturaihi@yahoo.com (R. S. Al-Turaihi), sarah.ha369@gmail.com (S. H. Oleiwi)
}

To cite this article:

Riyadh S. Al-Turaihi, Sarah H. Oleiwi. Experimental and CFD Investigation the Effect of Solid Particle Height in Water-Solid Flow in Fluidized Bed Column. International Journal of Mechanical Engineering and Applications. Vol. 3, No. 3, 2015, pp. 37-45. doi: 10.11648/j.ijmea.20150303.12

\begin{abstract}
The liquid solid fluidized beds have been usually used in catalytic cracking, ion exchange, crystallization, and particle classification. Fluidized bed column has investigated experimentally and numerically. A numerical investigation has been done by using computational fluid dynamic software ANSYS Fluent 15.0. In this study, a spherical stainless steel has used as solid particle fluidized continuously by water. Three different values of water flow rate $(10,15,20 \mathrm{l} / \mathrm{min})$ have used with three different values of static head of the solid particles $(2,2.5,3 \mathrm{~cm})$. The pressure of the fluidized bed has been measured at four different location of the test section $20 \mathrm{~cm}$ apart and the flow behavior at the test section has monitored by using AOS high speed camera. The experimental data has compared with numerical solution and a good agreement has been found. It can be observed that the expansion of the solid particles and the pressure inside the bed increased as the water flow rate and static bed height increased.
\end{abstract}

Keywords: Fluidized Bed, Two Phase Flow, CFD, Ansys Fluent

\section{Introduction}

Circulating fluidized beds (CFBs) have been commonly operated in chemical, petrochemical, ion exchange, metallurgical, adsorption, environmental, particle classification, and energy industries for applications such as fossil fuel combustion, coal and biomass gasification, and fluid catalytic cracking (FCC). Circulating fluidized beds have several significant advantages such as increased through-put, in-bed sulfur capture, fuel flexibility, and high efficiencies in gasification and combustion with relatively low emissions of NOx [1-2]. CFB technology is more attractive in the industry of energy than several other systems. Despite its extensive applications, the complex hydrodynamics of CFBs are still not completely understood and difficult to predict, in most applications, the heat and mass transfer between the phases and the chemical reactions make it even more difficult to predict the behavior of $\mathrm{CFB}$ reactors [2]. The solid particles placed on porous plate called distributor subsequently the continuous phase forced through the holes of distributor causing the particles suspension in the flowing flow, the solid particles expand in the bed and the expansion increase as the water flow rate increase. The fluidized bed subjected to research a long time ago. Tingwen et al. [2] have studied the grid refinement effect for a two circulating fluidized bed. Hashizume et al. [3] have studied experimentally the pressure drop for a liquid - solid fluidized bed with different diameters of particles. Kalaga et al. [4] have performed a liquid phase residence time distribution (RTD) study in a conventional solid liquid fluidized bed and in a solid liquid circulating multistage fluidized bed. AlTuraihi et al. [5] have investigated experimentally the steady state gas solid fluidized bed system with various materials of solid particles. Youjun $\mathrm{Lu}$ et al. [6] have studied experimentally the hydrodynamics of a supercritical water fluidized bed. Loha et al. [7] have investigated the influence of specularity coefficient on hydrodynamic behavior of fluidized bed with Geldert B particles using CFD Euler-Euler model. Leckner et al. [8] have studied the pressure fluctuations in a gas - solid fluidized bed by mean of a simple model of the principal frequency of the pressure fluctuations. Ramesh et al. [9] have obtained the gas holdup from the 
pressure drop and investigate the effect of composite promoter presence on the pressure drop for three phase fluidized bed. In this work, the bed pressure influenced by increasing water flow rate and the solid static height has investigated, the experimental result has compared with a result obtained by ANSYS Fluent 15.0 and a good agreement has been found.

\section{The Experimental Equipment and Procedure}

Figure (1) shows the schematic diagram of the TWO PHASE FLOW FLUIDIZE BED. The experiments were performed using Perspex circular cross section column with 1 $\mathrm{m}$ height and $0.0254 \mathrm{~m}$ diameter. Four taps $0.2 \mathrm{~m}$ apart along the test section side were used for pressure sensors with ranges from 0-1 bar that used to measure the pressure along the bed, the pressure sensor connected into a personal computer through data acquisition. The spherical stainless steel solid particles placed in the test column on a net with $0.334 \mathrm{~mm}$ hole spacing which represents the distributor, the water pumped with maximum discharge of $500 \mathrm{~L} / \mathrm{min}$ from the water tank and forced into the pipe through the holes of the distributor. 1 in valve used to control the flow rate of water Flow meter has used to measure volume flow rate of water with ranges from $5 \mathrm{l} / \mathrm{min}$ to $35 \mathrm{l} / \mathrm{min}$.AOS high speed camera has used to record the flow behavior inside the fluidized bed, the camera has active resolution of $720 \times 480$, and $29.97 \mathrm{~Hz}(59.94 \mathrm{~Hz}$ interlaced) image frequency with (SDTV 480i).

Three values of static head of solid particle $(\mathrm{H})$ have used and for each value the water flow rate has changed for three times. In order to make sure of the results, each test has repeated for three times. The used values are shown in table (1)

Table 1. The values used for the experiment.

\begin{tabular}{ll}
\hline $\mathbf{H}(\mathbf{c m})$ & Water flow rate $(\mathbf{l} / \mathbf{m i n})$ \\
\hline 2 & 10 \\
2.5 & 15 \\
3 & 20 \\
\hline
\end{tabular}

\section{Numerical Simulation}

For the numerical simulation Software ANSYS Fluent 15.0 has used for modeling water-solid flow. Eulerian approach was employed which sometimes called granular flow model (GFM), particles in the flow has treated as magnified molecules so that on analogy of their behavior to the continuous phase molecules can be stipulated [10]. For this work, the fluidized bed flow has modeled to be turbulent according to Reynolds number (for all the cases).

$$
R e=\frac{\rho u d}{\mu}
$$

Consequently K- $\varepsilon$ RNG mixture turbulent model has used.

\subsection{Geometry}

The test section which is $1 \mathrm{~m}$ height and $0.0254 \mathrm{~m}$ diameter pipe has modeled as two dimensional structure using Ansys Workbench 15.0. The bottom edge has been divided into 13 small edges as representation of distributor.

\subsection{Mesh}

Mesh has been carried out in ANSYS workbench 15.0 as well and Quad square mesh has been used to give 6500 element and 7014 node.

\subsection{Initial and Boundary Condition}

The bed initial volume fraction was set to be 0.7668 . The bottom edge set as velocity inlet and since its already divided into 13 pieces, one piece had gave the value of inlet velocity and the next gave zero inlet velocity respectively for all of them. The sides of the bed set to be walls and the top edge which is represent outlet of the bed set as outlet pressure and the values of the outlet pressure was taken from the experimental work.

\subsection{Post Processing}

The value of the bed pressure was measured by setting points with the same coordinate as the pressure sensor used in experimental test and the pressure measured at this points for the bed flow behavior, image for the solid volume fraction is taken every $2.5 \mathrm{sec}$ for all the experiment cases and the contour color set to be the same for all the experiment cases starting from 0 and ending with 0.2 . So, the difference in packing can be seen clearly.

The other parameters have used for the numerical simulation in fluent model are shown in table (2).

Table 2. Parameters used for the simulation.

\begin{tabular}{ll}
\hline Parameter & Value \\
\hline Drag model & Syamlal-O'Brien \\
Iteration/time step & 20 \\
Particle density & $8000 \mathrm{~kg} / \mathrm{m}^{3}$ \\
Particle diameter & $1.5 \mathrm{~mm}$ \\
Static bed height & $2,2.5,3 \mathrm{~cm}$ \\
Time step size & $0.0007 \mathrm{~s}$ \\
Under relaxation momentum & 0.2 \\
Under relaxation pressure & 0.3 \\
Under relaxation volume fraction & 0.5 \\
Water density & $998.2 \mathrm{~kg} / \mathrm{m}^{3}$ \\
Water superficial velocity & $0.33,0.49,0.66 \mathrm{~m} / \mathrm{s}$ \\
\hline
\end{tabular}

\subsection{The Governing Equations}

The general equations used by Eulerian multiphase model are the conservation of mass and momentum. Mass conservation equation can be written in its general form as

$$
\left.\frac{\partial}{\partial t}\left(\alpha_{q} \rho_{q}\right)+\nabla \cdot\left(\alpha_{q} \rho_{q} \overrightarrow{v_{q}}\right)=\sum_{p=1}^{n} m_{p q}-m_{q p}\right)+S_{q}
$$

The source term $S_{q}$ is zero as default value or else it can be a set constant value or define by user. Momentum 
conservation equation can be written in its general form as

$$
\begin{aligned}
& \frac{\partial}{\partial t}\left(\alpha_{q} \rho_{q} \overrightarrow{v_{q}}\right)+\nabla \cdot\left(\alpha_{q} \rho_{q} \overrightarrow{v_{q}} \overrightarrow{v_{q}}\right)=-\alpha_{q} \nabla p+\nabla \cdot \bar{\tau}_{q}+ \\
& \alpha_{q} \rho_{q} \vec{g}+\sum_{p=1}^{n}\left(\vec{R}_{p q}+\dot{m}_{p q} \vec{v}_{p q}-\dot{F}_{l i f t, q}+\vec{F}_{q p, q}\right)+
\end{aligned}
$$

Where $\overline{\bar{\tau}}_{q}$ is the stress - strain tensor.

$$
\overline{\bar{\tau}}_{q}=\alpha_{q} \mu_{q}\left(\nabla \vec{v}_{q}+\nabla \vec{v}_{q}^{T}\right)+\alpha_{q}\left(\lambda_{q}-\frac{2}{3} \mu_{q}\right) \nabla \cdot \vec{v}_{q} \overline{\bar{I}}
$$

$\mathrm{q}$ Represent the phase in all equations

\section{Result and Discussion}

\subsection{Experimental Results}

The pressure of fluidized bed is used to characterize the bed and it depends on the volume flow rate of continuous phase wither its liquid, gas or mixture of both, the physical properties of solid and continuous phases, static bed height (the quantity of solid placed in the fluidized bed) and the geometry of the test section. In this experiment the pressure has measured at four taps on the test section to find the effect of increasing volume flow rate of water and static bed height on the profile of the pressure at different location along the test pipe. Figure (2) shows the effect of increasing water flow rate on the pressure profile along the test section at four different locations where the pressure taps exist which is 0.2 $\mathrm{m}$ apart with respect to the static bed height. Three different values of water flow rate were shown at each value of static bed height and for three values of static bed height, as the volume flow rate increased the pressure of the bed increased due to the increase in the density of the mixture as well as the increase in the expansion of the bed as the water flow rate increase. Figure (3) shows the effect of static bed height on the pressure profile with respect to the water volume flow rate, the pressure inside the bed increases as the static bed height increases. The flow behavior in the test section as the flow rate of water increase at different values of bed height are shown in figures ( $4 a, 5 a, 6 a)$ which is taken for the test section by using high speed camera- .The camera can monitor only $0.6 \mathrm{~m}$ of the test section which is $1 \mathrm{~m}$. In these figures the expansion of the bed can be seen which increases as the flow rate increase. Figures ( $7 a, 8 a, 9 a)$ shows the flow behavior in the test section as the static bed height increase with respect to the change in the water flow rate, the expansion of the bed increase as the value of static head of solid particle(H) increased in the pipe.

\subsection{Numerical Simulation}

The experimental result of pressure have compared with computational fluid dynamics results obtained using ANSYS Fluent 15.0 and a good agreement has been found as can be seen in figure (2). The two phase flow is a changing phenomena due to distribution of the solid particles are different each time for the same experiment. Figure (3) shows a comparison between the pressure results as the static bed height changed with respect to the water flow rate. Figures $(4,5,6)$ show the solid particle distribution of experimental test and the solid particle distribution from Fluent program for the solid volume fraction, which shows the flow behavior in the test section as the water flow rate increases for different values of the static bed height for 0.4 $\mathrm{m}$ for each test. Fluent program gave a good result for the expansion of the bed as the flow rate changes, however the results is not exact match between the experimental and numerical results that because the images taken from the program for the same time but in the experimental work it taken at different times during the experiment. Figures $(7,8$, and 9) show compaction between the flow behavior as the value of static head of solid particle $(\mathrm{H})$ increases for different values of water flow rate. The contour color for all the experiment is same which is between 0 to 0.2 it can help to see the differences in the packing and spaces between the particles as the flow rate or $\mathrm{H}$ increases.

\section{Conclusion}

In this work, the two phase fluidized bed has studied experimentally and numerically by using ANSYS Fluent. The pressure of the bed has measured at different points along the bed and the behavior of the flow has monitored (or recorded) by using high speed camera which is then compared with the solid volume fraction of bed found by ANSYS Fluent15.0. Three different values of $\mathrm{H}$ and water flow rate have used. It can be concluded that

- As the volume flow rate of water increase the pressure of the bed will be increase.

- As the value of $\mathrm{H}$ increase the pressure of the bed will be increase.

- As the volume flow rate of water increase the expansion of the bed will be increase.

- As the value of $\mathrm{H}$ increase the expansion of the bed will be increase. 


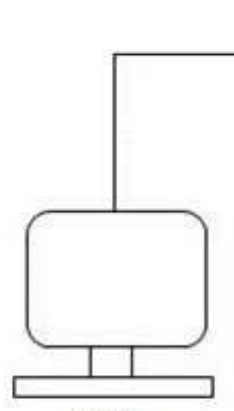

(11)

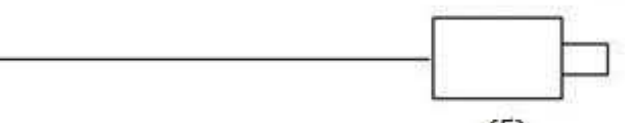

(5)

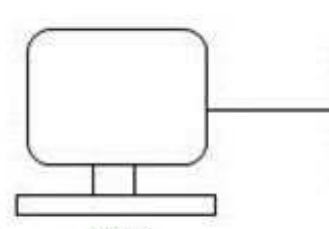

(10)

(7)
1- Test section (25.4 mm Dia.)

2-Distributor

3- Water valve

4- Water flow meter

5 - AOS high speed camera

6- Pressure sensor
7- Data acquisition

8- Water pump

9- Water tank

10- PC computer

11- PC computer
(1)
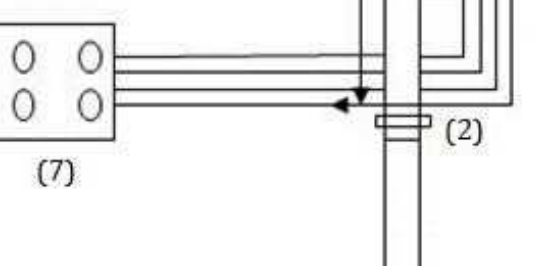

(3)

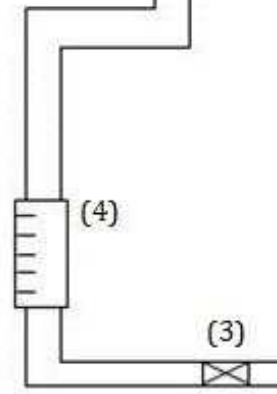

(8)

Fig. 1. The experiment schematic diagram.
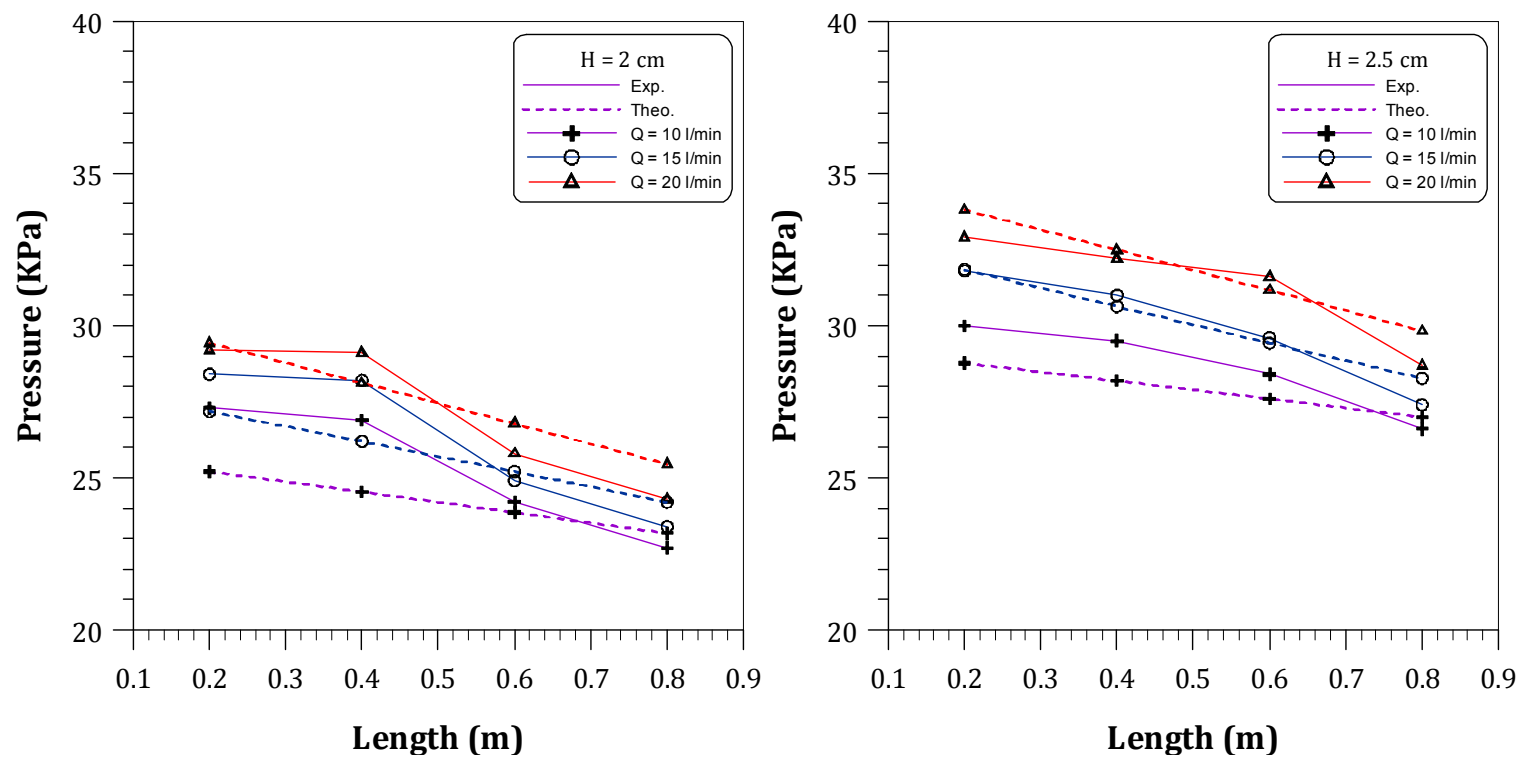
41 Riyadh S. Al-Turaihi and Sarah H. Oleiwi: Experimental and CFD Investigation the Effect of Solid Particle Height in Water-Solid Flow in Fluidized Bed Column

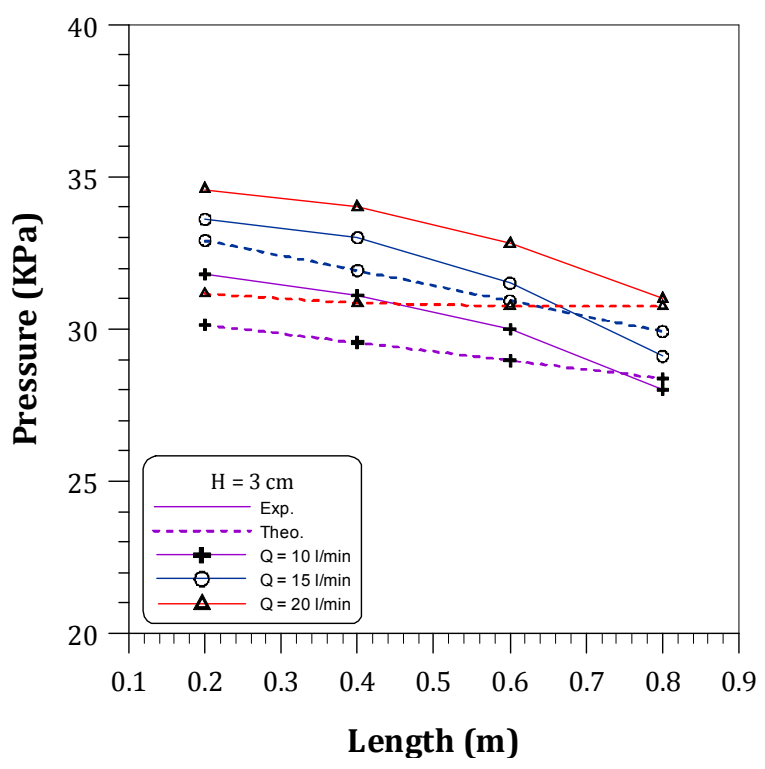

Fig. 2. Effect of water flow rate on pressure profile.
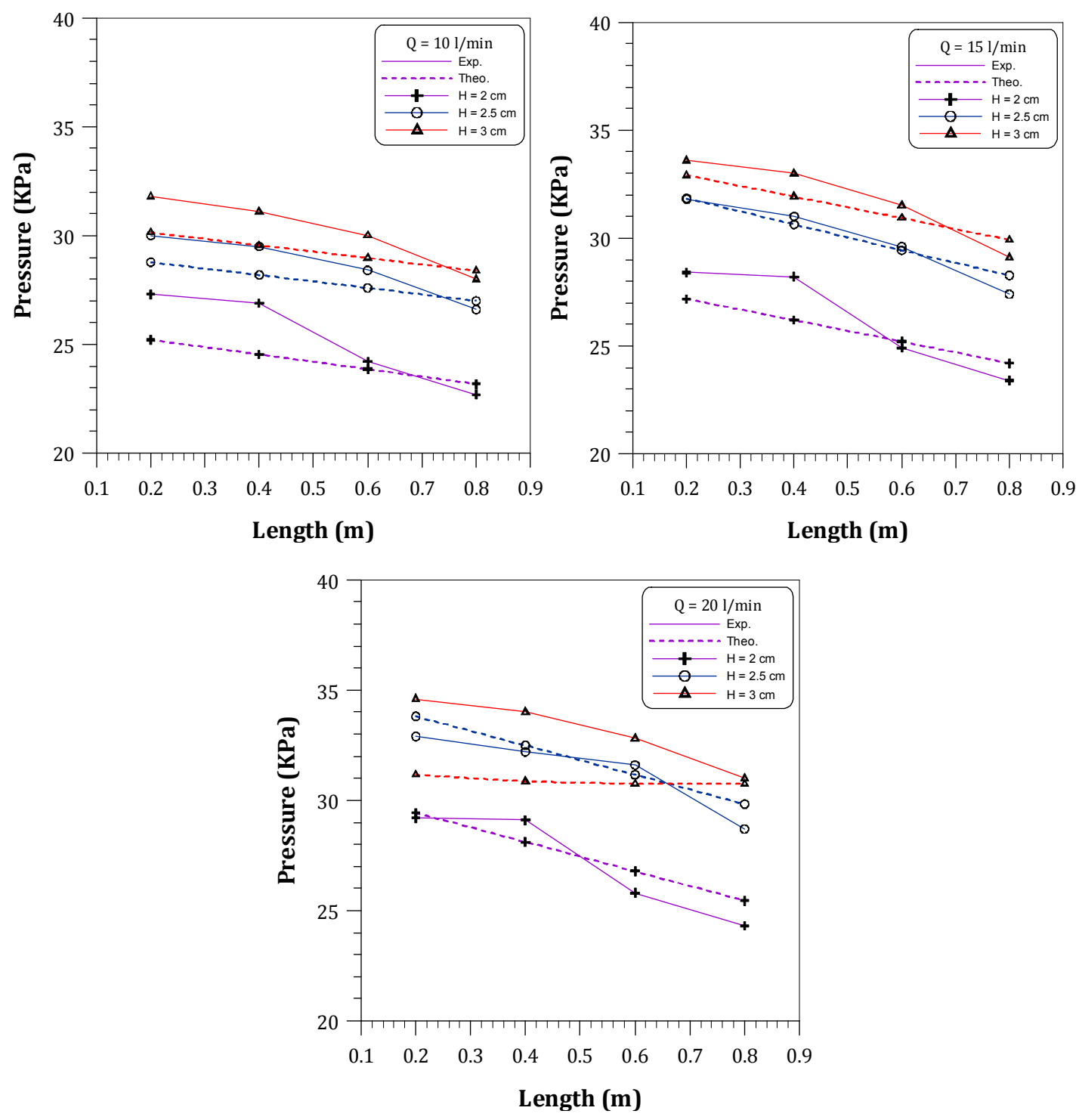

Fig. 3. Effect of $H$ on pressure profile. 

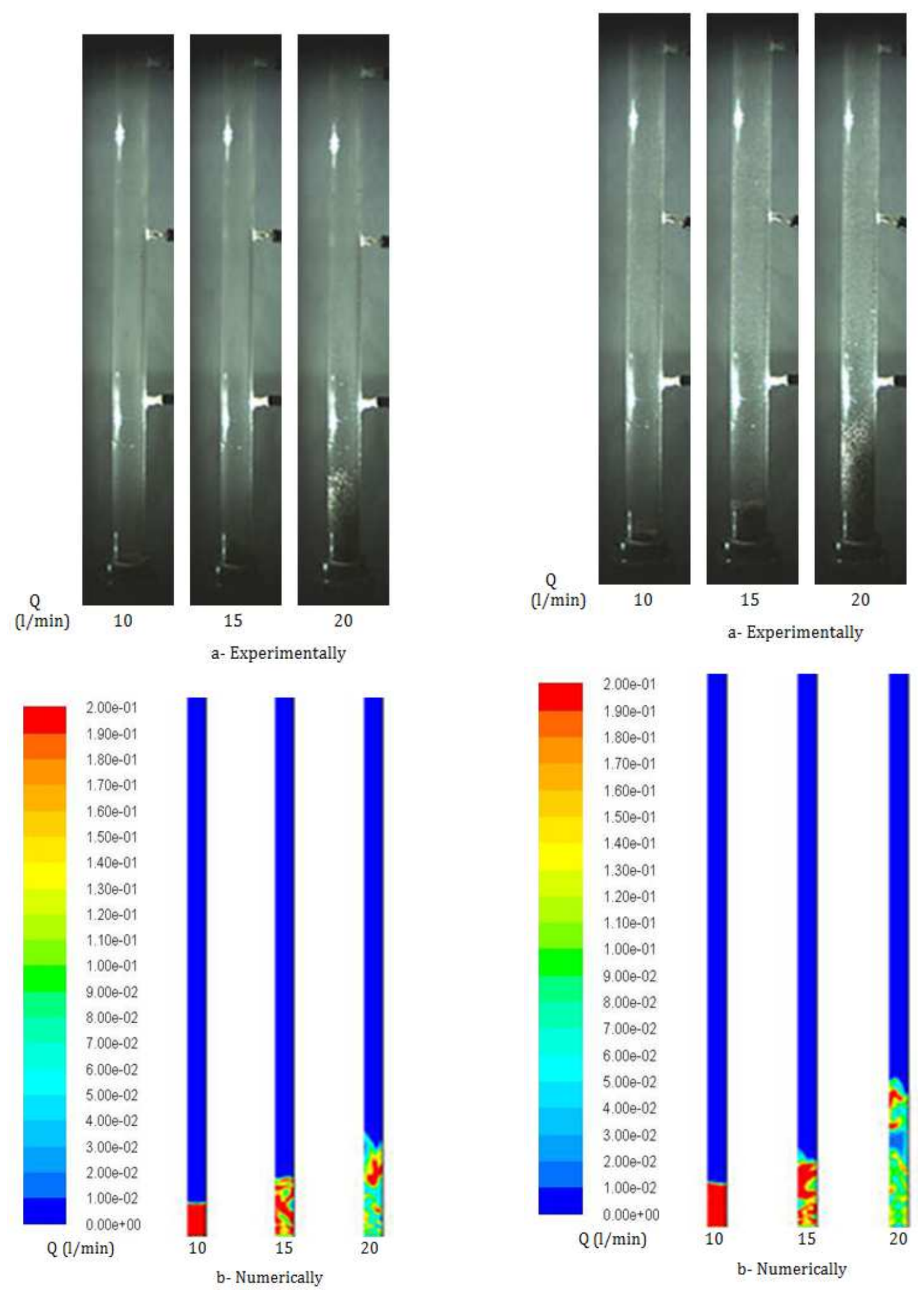

Fig. 4. Flow behavior at $2 \mathrm{~cm} H$ and different values of water flow rate.

Fig. 5. Flow behavior at $2.5 \mathrm{~cm} \mathrm{H}$ and different values of water flow rate. 

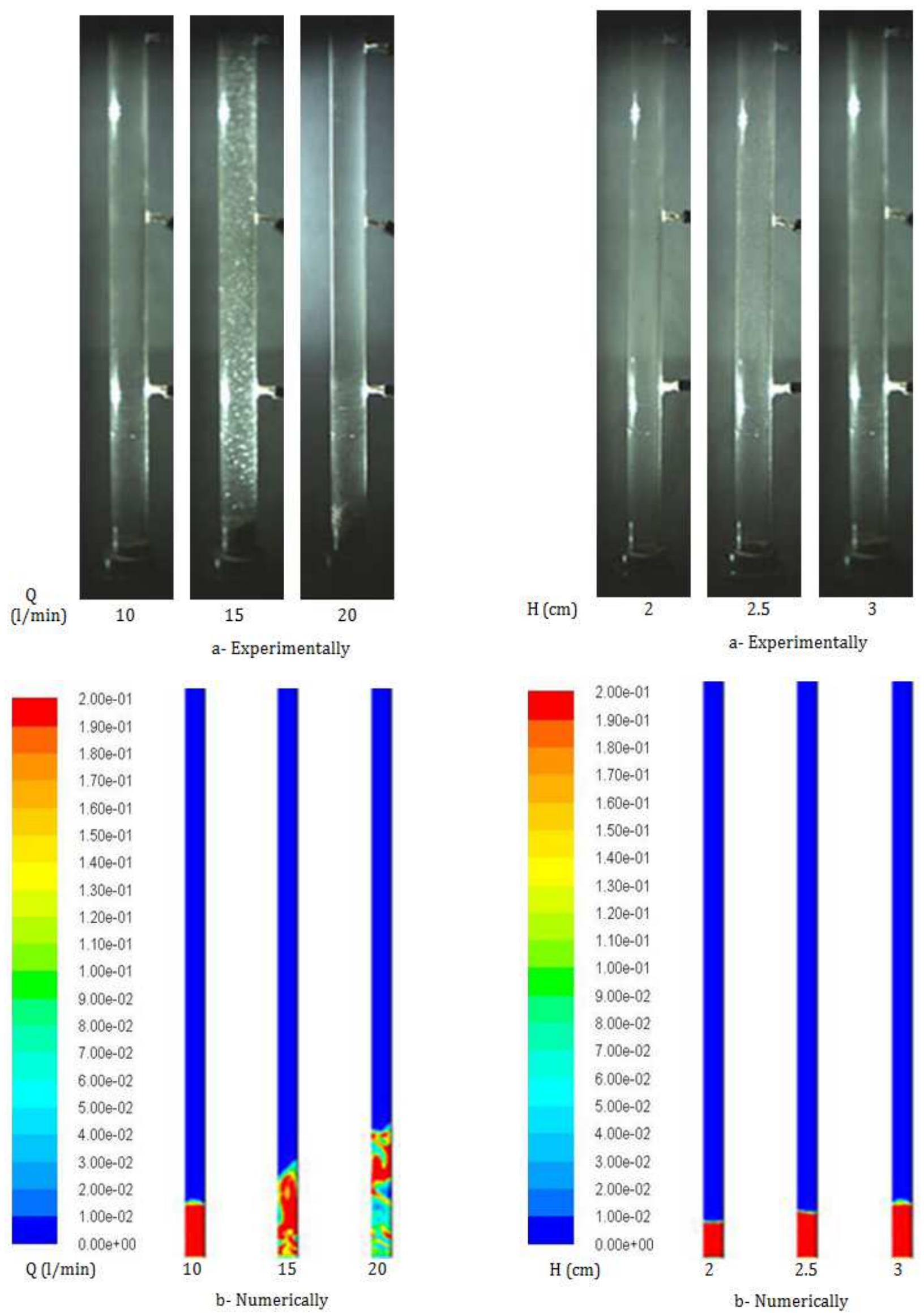

Fig. 6. Flow behavior at $3 \mathrm{~cm} \mathrm{H}$ and different values of water flow rate.

Fig. 7. Flow behavior at $10 \mathrm{l} / \mathrm{min}$ water flow rate and different values of $\mathrm{H}$. 

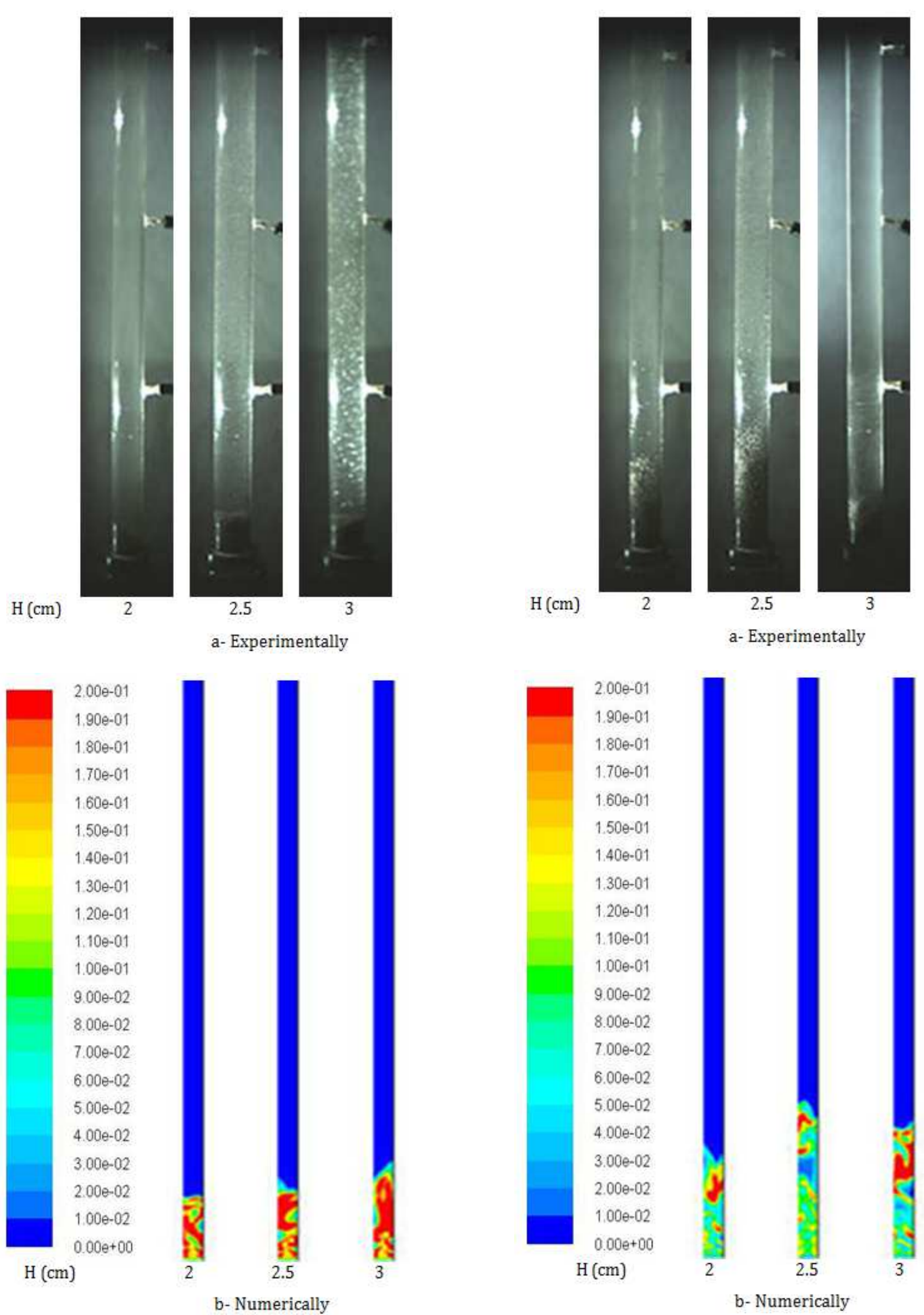

Fig. 8. Flow behavior at $15 \mathrm{l} / \mathrm{min}$ water flow rate and different values of $H$.

Fig. 9. Flow behavior at $20 \mathrm{l} / \mathrm{min}$ water flow rate and different values of $\mathrm{H}$. 


\section{Nomenclature}

H: Static bed height (cm)

CFD: Computational fluid dynamics

$\mathrm{F}_{\mathrm{q}}$ : External force $(\mathrm{N})$

$\mathrm{G}$ : Gravity acceleration $\left(\mathrm{m} / \mathrm{s}^{2}\right)$

$\mathrm{K}_{\mathrm{pq}}$ : Exchange coefficient

q: Number of phases

Q: Water flow rate $(1 / \mathrm{min})$

$\mathrm{m}_{\mathrm{pq}}$ : Interphase mass exchange $\left(\mathrm{kg} / \mathrm{m}^{3} . \mathrm{s}\right)$

Greek symbols

$\varepsilon$ : Epsilon

$\alpha_{\mathrm{q}}$ : Volume fraction for the $\mathrm{q}^{\text {th }}$ phase

$\rho_{\mathrm{q}}$ : Mixture density for the $\mathrm{q}^{\text {th }}$ phase $\left(\mathrm{kg} / \mathrm{m}^{3}\right)$

$\tau_{\mathrm{q}}$ : Shear stress for the $\mathrm{q}^{\text {th }}$ phase

Subscripts

A: Air

C: Continuous phase

lift: Lift force

q: Secondary phase

vm: Virtual mass force

\section{References}

[1] Reza Davarnejad, Reza Eshghipour, Jafar Abdi and Farhad Banisharif Dehkordi, "CFD Modeling of a Binary LiquidSolid Fluidized Bed", Middle-East Journal of Scientific Research, 19 (10): 1272-1279, 2014.

[2] Tingwen Li, Aytekin Gel, Sreekanth Pannala, Mehrdad Shahnam, Madhava Syamlal, "CFD simulations of circulating fluidized bed risers, part I: Grid study", Powder Technology, $254-170-180,2014$.

[3] Kenichi Hashizume, Shinichi Morita, Yuki Nakamura, and Akira Wada," Pressure Drop in Liquid-Solid Circulating Fluidized Beds", Heat Transfer-Asian Research, 38 (4), 2009.
[4] Dinesh V. Kalaga, Rupesh K. Reddy, Jyeshtharaj B. Joshi, Sameer V. Dalvi, K. Nandkumar, "Liquid phase axial mixing in solid-liquid circulating multistage fluidized bed: CFD modeling and RTD measurements", Chemical Engineering Journal, 191- 475-490, 2012.

[5] Riyadh S. Al-Turaihi, Ahmed Kadhim Hussein, Hussain H. Al-Kayiem and H. A. Mohammed, "Experimental Investigation of Various Solid Particle Materials on the Steady State Gas-Solid Fluidized Bed System”, J. Basic. Appl. Sci. Res., 3(7)293-304, 2013.

[6] Youjun Lu, Liang Zhao, Qiang Han, Liping Wei, Ximin Zhang, Liejin Guo, Jinjia Wei, "Minimum fluidization velocities for supercritical water fluidized bed within the range of 633-693 $\mathrm{K}$ and 23-27 MPa", International Journal of Multiphase Flow, $49-78-82,2013$

[7] Chanchal Loha, Himadri Chattopadhyay, Pradip K. Chatterjee, "Euler-Euler CFD modeling of fluidized bed: Influence of specularity coefficient on hydrodynamic behavior", Particuology, 11- 673-680, 2013.

[8] Bo LECKNER, Genadij I. PALCHONOK, and Filip JOHNSSON, "PRESSURE FLUCTUATIONS IN GAS FLUIDIZED BEDS", Original scientific paper, 0354-9836, 6 , 2, 3-11, 2002.

[9] K.V. Ramesh, G.M.J. Raju, G.V.S. Sarma, C. Bhaskara Sarma, "Effect of internal on phase holdups of a three-phase fluidized bed", Chemical Engineering Journal, 145-393-398, 2009.

[10] Farshid Vejahati, Nader Mahinpey, Naoko Ellis and Mehrdokht B. Nikoo, "CFD Simulation of Gas-Solid Bubbling Fluidized Bed: A New Method for Adjusting Drag Law", Can. J. Chem. Eng., 87:19-30, 2009.

[11] Ansys 13.0 Help, Fluent Theory Guide, Mixture Multiphase Model.

[12] Ansys Fluent Tutorials, Fluidized bed. 